\title{
Matérista
}

Revista Matéria, v. 14, n. 2, pp. 845 - 860, 2009

ISSN 1517-7076

http://www.materia.coppe.ufrj.br/sarra/artigos/artigo11056

\section{Dielétrico de vidro de elevada confiabilidade mecânica e termomecânica produzido por têmpera de dois estágios (têmpera térmica + troca iônica)}

\author{
YOSHIMURA, H.N.'; GUEDES, S. II, FREDECICCI, C. ${ }^{\text {III }}$ \\ ${ }^{\text {I } U n i v e r s i d a d e ~ F e d e r a l ~ d o ~ A B C ~-~ U F A B C, ~ R u a ~ S a n t a ~ A d e ́ l i a, ~ 166, ~ C E P: ~ 09210-170, ~ S a n t o ~ A n d r e ́, ~ S P . ~}$ \\ e-mail: humberto.yoshimura@ufabc.edu.br \\ ${ }^{\text {II }}$ Prismatic Vidros de Precisão S.A., Av. John Boyd Dunlop, 1230, CEP: 18087-155, Sorocaba, SP \\ e-mail: s.guedes@prismatic.com.br

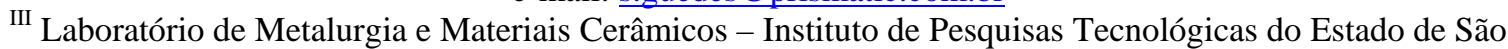 \\ Paulo - IPT, Av. Prof. Almeida Prado, 532, CEP: 05508-901, São Paulo, SP. \\ e-mail: catiaf@ipt.br
}

\section{RESUMO}

Neste trabalho, investigou-se a possibilidade de se aumentar o desempenho mecânico e termomecânico do dielétrico de vidro por meio do tratamento de têmpera de dois estágios, têmpera térmica seguida de troca iônica de curto período. Os dielétricos de vidro de silicato sodo-cáustico foram produzidos por meio de prensagem em uma linha industrial, sendo que a têmpera térmica foi realizada com resfriamento brusco a partir de $580^{\circ} \mathrm{C}$ utilizando jatos de ar em um dispositivo rotativo (tournettes) e a troca iônica foi realizada em um banho de $\mathrm{KNO}_{3}$ a $450^{\circ} \mathrm{C}$ por $30 \mathrm{~min}$. $\mathrm{O}$ dielétrico tratado pelo método de têmpera de dois estágios apresentou, em relação ao dielétrico convencional (temperado termicamente), melhores desempenhos nos ensaios de choque térmico (aquecimento, resfriamento e ciclagem térmica) e maiores valores de módulo de Weibull, $\mathrm{m}$, da força de ruptura em compressão e do tempo de ruptura no choque térmico de aquecimento, enquanto manteve elevadas as propriedades mecânicas (força de ruptura em compressão e energia absorvida no impacto), nos níveis alcançados na têmpera térmica. Os efeitos causados pelo segundo estágio (troca iônica) são discutidos em termos de formação de um perfil de tensão residual favorável ao aumento da confiabilidade mecânica e termomecânica do dielétrico, como conseqüência da atuação simultânea dos mecanismos de estufamento iônico e relaxação de tensão durante o tratamento de troca iônica.

Palavras chaves: Dielétrico, vidro, têmpera, troca iônica, propriedades mecânicas, choque térmico, análise de Weibull, confiabilidade.

\section{Glass dielectric with high mechanical and thermomechanical reliability produced by two-step tempering (thermal tempering + ion exchange) ABSTRACT}

In this work, the possibility to enhance the mechanical and thermomechanical performance of glass dielectric by the two-step tempering, short-time ion exchange following thermal tempering, was investigated. The soda-lime silicate glass dielectrics were produced by pressing in an industrial plant, where the thermal tempering was conducted with quenching from $580^{\circ} \mathrm{C}$ using forced air in a tempering fixture (tournettes) and the ion exchange was performed using a $\mathrm{KNO}_{3}$ bath at $450^{\circ} \mathrm{C}$ for $30 \mathrm{~min}$. The dielectric treated by the twostep tempering method showed, in relation to the conventional dielectric (thermal tempered), better performances in the thermal shock tests (heating, cooling and thermal cycling) and higher values of Weibull modulus, m, for breaking load in compression and for breaking time in heating thermal shock, while the mechanical properties (breaking load in compression and absorbed energy in impact) remained high, at the levels achieved by the thermal tempering. The effects caused by the second stage (ion exchange) are discussed in terms of the formation of a residual stress profile which enhances the mechanical and thermomechanical reliability, as a consequence of simultaneous action of ion-stuffing and stress relaxation mechanisms during the ion exchange treatment.

Keywords: Dielectric, glass, tempering, ion exchange, mechanical properties, thermal shock, Weibull analysis, reliability. 


\section{INTRODUÇÃO}

Os dielétricos de vidro temperado são componentes utilizados em isoladores elétricos de linhas de transmissão e de distribuição de energia elétrica e devem apresentar confiabilidade operacional para suportar o clima e as condições de poluição das cidades e metrópoles [1]. Os isoladores com dielétricos de vidro temperado isolam eletricamente a linha da terra e sustentam mecanicamente os cabos aéreos de energia fixados nos postes [2]. Os isoladores elétricos com dielétricos de vidro apresentam vantagens de desempenho em elevadas temperaturas e em condições agressivas de umidade e poluição em relação aos isoladores com dielétricos de porcelana e de polímeros, entretanto, têm uma limitação relacionada à fragilidade característica que apresentam os materiais vítreos [3] . A incidência de falhas nos isoladores de vidro não é muito comum, porém é um problema grave quando se trata de uma linha de alta tensão, pois a falha de um único elemento pode comprometer seriamente o fornecimento de energia [3]]. Os distúrbios causados pelas descargas atmosféricas são um dos maiores problemas para a continuidade do suprimento de energia, sendo que o Brasil é o país no qual ocorre a maior incidência de raios $[\underline{4}, \underline{5}]$. Os surtos atmosféricos podem causar danos aos isoladores por meio dos elevados esforços de sobretensão, pelas correntes do próprio raio ou pelo arco de potência resultante da disrupção (geração de faísca) do isolador [్].

Os dielétricos de vidro são temperados termicamente para se aumentar a resistência mecânica, a resistência ao impacto e a resistência ao choque térmico [2]. No processo de têmpera térmica, o vidro é aquecido a uma temperatura entre as temperaturas de recozimento superior e de amolecimento e, posteriormente, resfriado rapidamente, usualmente, com ar frio forçado. Durante o estágio de resfriamento brusco, a região externa da peça de vidro resfria-se rapidamente enquanto o núcleo interno contrai-se e resfria-se mais lentamente. Quando o vidro resfria e alcança a temperatura uniforme, um perfil de tensão de compressão é introduzido na superfície e, em compensação, um perfil de tensão de tração é desenvolvido no seu interior [ $[\underline{6}, \underline{7}]$. Devido à distribuição de tensão residual ser parabólica, a magnitude da tensão de compressão na superfície é o dobro da tensão de tração no centro do vidro [8]]. Tensões de compressão da ordem de $150 \mathrm{MPa}$ podem ser alcançadas pelo processo de têmpera térmica, dependendo da espessura do vidro, do coeficiente de transferência de calor e dos parâmetros do tratamento térmico [ $\underline{6}]$.

Outro processo que resulta na formação de um estado de tensão de compressão na superfície do vidro é a têmpera química. Neste processo, o vidro é imerso em um banho de sal fundido a uma temperatura abaixo da temperatura de transição vítrea, $\mathrm{T}_{\mathrm{g}}$, para ocorrência do fenômeno de troca iônica, onde um cátion do vidro é substituído por um cátion de maior volume do banho de sal. Esta troca acarreta no efeito de estufamento iônico (ion stuffing) da superfície, causando a formação de uma camada superficial de tensão compressiva permanente $[\underline{9}, \underline{10}]$. O processo de têmpera química pode resultar em magnitudes de tensão de compressão na superfície até três vezes maiores do que as obtidas pela têmpera térmica [6] . A resistência mecânica do vidro temperado quimicamente depende de dois fenômenos que atuam simultaneamente durante a troca iônica: i) geração de tensão induzida pela diferença de tamanho entre os íons trocados; e ii) relaxação de tensão causada pela acomodação dos íons na rede do vidro por meio difusional e viscoso. Em decorrência dos fenômenos de geração e relaxação de tensão, a resistência mecânica tende a apresentar um valor máximo em função do tempo de tratamento [11]. Uma das características da têmpera química é a formação de um gradiente de tensão de compressão agudo, isto é, de alta magnitude na superfície, que diminui rapidamente de forma linear em uma pequena distância a partir da superfície. Como resultado, forma-se uma larga região central com tensão de tração constante e de baixa intensidade [12]. Uma das limitações associadas ao tratamento de têmpera química é o tempo de processamento geralmente longo para se obter uma profundidade de camada de troca iônica suficientemente espessa (da ordem de $100 \mu \mathrm{m}$ ), necessária para que o vidro temperado suporte danos superficiais profundos decorrentes de riscamento e impacto [13]. Para vidros de silicato sodo-cálcico, a têmpera química tem sido realizada em sal fundido a base de $\mathrm{KNO}_{3}$ a $\sim 450^{\circ} \mathrm{C}$ por tempos de até 24 h [14], onde os íons de $\mathrm{Na}^{+}$do vidro, com diâmetro iônico de 1,90 Å, são substituídos pelos íons de $\mathrm{K}^{+}$do banho de sal, com diâmetro iônico de 2,66 Å [토] .

Os aumentos de resistência mecânica proporcionados pelos processos de têmpera térmica e química, entretanto, não têm sido suficientes para se aumentar expressivamente os valores de resistência de projeto (design strength) do produto vítreo, devido à presença de uma fração do produto temperado com baixa resistência mecânica [16]. Recentemente, tem sido proposto que a confiabilidade mecânica do vidro temperado pode ser aumentada pela aplicação de tratamentos de têmpera de dois ou mais estágios, envolvendo os processos de têmpera térmica e/ou química. Os tratamentos multi-estágios têm sido propostos para resultar em um perfil de tensão residual controlado (engineered stress profile), com o valor de máxima tensão de compressão deslocado a uma determinada profundidade da superfície. Isto dificulta o crescimento da trinca na região superficial, pois à medida que a trinca avança aumenta-se o nível de tensão de compressão na ponta da mesma [17, 18]. Green et al. [18] aplicaram o tratamento de têmpera por troca iônica de dois estágios em um vidro de alumino-silicato sódico, onde a primeira troca foi realizada em um banho de $\mathrm{KNO}_{3}$ por $24 \mathrm{~h}$ a $500^{\circ} \mathrm{C}$, para incorporação de $\mathrm{K}^{+}$do banho em substituição ao $\mathrm{Na}^{+}$do vidro, e a segunda troca foi realizada em um banho de sal contendo $30 \%$ em mol de $\mathrm{NaNO}_{3}$ e $70 \%$ em mol de $\mathrm{KNO}_{3}$ por 30 min a $400^{\circ} \mathrm{C}$, 
para remoção parcial de $\mathrm{K}^{+}$introduzido na primeira troca no vidro por $\mathrm{Na}^{+}$do banho. Este tratamento resultou no perfil de tensão de compressão crescente a partir da superfície até um valor máximo na profundidade de $\sim 25 \mu \mathrm{m}$, que em seguida diminuiu com o aumento da distância da superfície. O vidro submetido ao tratamento de dois estágios apresentou dispersão de resultados de tensão à ruptura significativamente menor do que a do mesmo vidro recozido (valores de coeficiente de variação, CV, de resistência à flexão de $2,4 \%$ e $\sim 20 \%$, respectivamente). Além disso, o vidro tratado por troca iônica de dois estágios, quando solicitado em flexão, apresentou formação de múltiplas trincas superficiais (da largura da chapa), mas de pequena profundidade, na face submetida à tensão de tração, antes da ocorrência da fratura final. Estes resultados mostraram que o controle do perfil de tensão residual de compressão possibilita o arresto e o crescimento estável de trincas superficiais de diferentes tamanhos, quando o vidro é submetido a carregamentos crescentes, sendo que a fratura ocorre em um valor de tensão (e comprimento de trinca) aproximadamente constante, independente do tamanho inicial do defeito, minimizando a variabilidade da resistência mecânica [18]. O perfil crescente de tensão residual de compressão equivale a um perfil de aumento da tenacidade à fratura aparente, isto é equivalente ao comportamento de curva R crescente [19, 20]. Sglavo e Green [21] propuseram que a ocorrência de formação de múltiplas trincas na superfície depende da formação de um forte gradiente de tensão de compressão, que é definido pela segunda troca iônica. Abrams et al. [22, 23] mostraram que a aplicação do tratamento de troca iônica de dois estágios em um vidro de silicato sodo-cáustico também foi efetiva para formação de um perfil de tensão residual controlado e conseqüente formação de múltiplas trincas superficiais e diminuição da dispersão dos resultados de resistência mecânica. Um vidro float tratado em banho de $\mathrm{KNO}_{3}$ a $450^{\circ} \mathrm{C}$ por $48 \mathrm{~h}$ e em seguida em banho de $63 \% \mathrm{KNO}_{3}-37 \% \mathrm{NaNO}_{3}(\% \mathrm{em} \mathrm{mol})$ a $400^{\circ} \mathrm{C}$ por $30 \mathrm{~min}$ apresentou resistência à flexão de $308 \pm 12 \mathrm{MPa}$ $(\mathrm{CV}=4 \%)$ e módulo de Weibull, $\mathrm{m}$, de 38 , cujos valores foram significativamente maiores do que os do vidro recozido (94 $\pm 14 \mathrm{MPa}$; $\mathrm{CV}=15 \%$; $\mathrm{m}=4,5)$ [22].

O perfil de tensão controlado, introduzido por tratamento de troca iônica de dois estágios, é um avanço significativo na direção do aumento e controle da resistência mecânica dos materiais vítreos. Estes materiais comumente falham de forma súbita (com conseqüências muitas vezes catastróficas), quando submetidos a tensões mecânicas e térmicas. A formação de múltiplas trincas superficiais antecedendo a fratura final indica que o vidro com perfil de tensão controlado pode apresentar certo grau de segurança contra defeitos superficiais, embora inerentemente frágil [18]. Estas trincas também podem atuar como um "aviso" da proximidade da fratura final, o que possibilita descarregar o vidro antes que ocorra a fratura catastrófica [21]. Outra característica significativa do vidro com perfil de tensão controlado é a sua alta confiabilidade mecânica. Estes comportamentos podem ser explorados em muitas aplicações tecnológicas dos vidros e, também, de outros materiais cerâmicos, permitindo esses serem usados de modos mais confiáveis [18]. Em decorrência do processo de tratamento de têmpera por troca iônica de dois estágios ser oneroso, Shen e Green [24] propuseram um método denominado "troca iônica com temperatura variável" para introduzir o perfil de tensão residual controlado, utilizando apenas um banho de sal e realizando um estágio de troca iônica a alta temperatura em curto tempo, antes da troca iônica convencional. Este método aplicado a um vidro float (silicato sodo-cáustico), utilizando banho de $\mathrm{KNO}_{3} \mathrm{com}$ primeiro estágio a $550^{\circ} \mathrm{C}$ por 15 min e segundo estágio a $475^{\circ} \mathrm{C}$ por $18 \mathrm{~h}$, resultou na prevista diminuição da variabilidade da resistência mecânica (CV de 3,3\% contra 6,4\% no vidro tratado por têmpera química convencional - $\mathrm{KNO}_{3}$, $475^{\circ} \mathrm{C}, 18$ h), mas acompanhada de diminuição de 11\% da resistência (293 MPa contra $330 \mathrm{MPa}$ ) [24]. Estes resultados exemplificam um dos desafios dos tratamentos multi-estágios, que é a de resultar em aumento da confiabilidade mecânica ao mesmo tempo em que mantém a resistência mecânica elevada. Embora o método proposto de troca iônica com temperatura variável [24] seja mais simples que o de têmpera por troca iônica de dois estágios, ele ainda é oneroso, pois envolve um tratamento de troca iônica de longo tempo.

Os dielétricos de vidro são produzidos por têmpera térmica, o que leva a um interesse em se desenvolver um tratamento para se aumentar a confiabilidade mecânica e termomecânica destes produtos, que seja aplicável após a têmpera térmica, mas que não aumente significativamente o custo de produção. Schaeffer [17] listou uma série de possibilidades de tratamentos de têmpera multi-estágios, incluindo têmpera térmica seguida por troca iônica ou "têmpera térmica inversa” (aquecimento rápido, por exemplo, com imersão em banho metálico), para relaxação parcial da tensão compressiva superficial, mas não apresentou as condições dos tratamentos e nem resultados ou desempenho destes processos. Praticamente não há registros na literatura sobre a aplicabilidade destes métodos, sendo exceção o trabalho de Anusavice et al. [25], que investigaram o efeito da aplicação da troca iônica de curto tempo (30 min), após a têmpera térmica, em uma porcelana para aplicação dentária e verificaram que este processo resultou, ao contrário do esperado, em diminuição de $11 \%$ na resistência à flexão (183,2 MPa contra 205,5 MPa da amostra somente temperada termicamente). Observaram, entretanto, aumento da confiabilidade mecânica (aumento do módulo de Weibull) na amostra temperada em dois estágios, mas o pequeno número de corpos-de-prova utilizado (seis) dificultou a análise [25]. 
Neste trabalho, explorou-se a possibilidade de se aumentar o desempenho mecânico e termomecânico do dielétrico de vidro por meio do tratamento de têmpera de dois estágios, aplicando um tratamento de têmpera química de curto período, após a têmpera térmica. O segundo estágio do tratamento (troca iônica em $\mathrm{KNO}_{3}$ a $450^{\circ} \mathrm{C}$ por $30 \mathrm{~min}$ ) foi realizado para a incorporação de $\mathrm{K}^{+}$do banho em substituição ao $\mathrm{Na}^{+}$do vidro, sendo, portanto, operacionalmente parecido, mas com função oposta a do segundo estágio do tratamento de troca iônica de dois estágios de Abrams et al. [22]. A aplicação de um tratamento de troca iônica de curto período no segundo estágio tem a vantagem de ser significativamente menos oneroso do que os tratamentos de troca iônica de dois estágios ou com temperatura variável, que envolvem tratamentos convencionais de longo período (acima de $12 \mathrm{~h}$ ). Este trabalho foi realizado no âmbito de um projeto de desenvolvimento de uma rota de produção de dielétrico de vidro temperado para REM (resistência eletro-mecânica) de 45 kN com elevada confiabilidade mecânica e termomecânica. O objetivo deste trabalho foi investigar as influências da aplicação de um tratamento de troca iônica após a têmpera térmica nas propriedades mecânicas e termomecânicas do dielétrico de vidro.

\section{MATERIAIS E MÉTODOS}

A produção do dielétrico de vidro de silicato sodo-cálcico (Figura 1, Tabela 1) foi realizada utilizando-se como matérias-primas areia (sílica, Mineração Jundú), barrilha (carbonato de sódio, Edelbras), calcita (carbonato de cálcio, Mineração Jundú), feldspato (silicato de alumínio com sódio e potássio, Becomi), nitrato de sódio (Manchester), barita (sulfato de bário, Becomi), trióxido de antimônio (Oxy Química), selênio (JB Química), óxido de cobalto (Edelbras) e cacos de vidro de retorno interno.
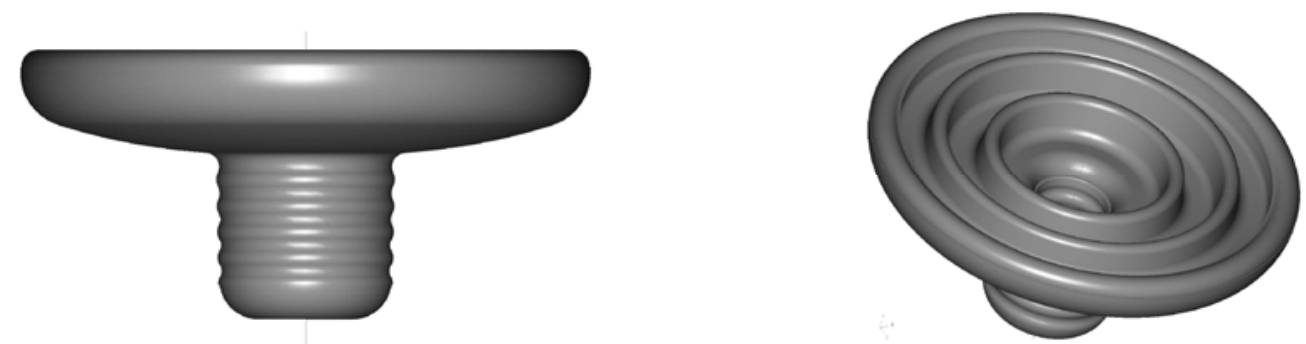

Figura 1: Imagens do dielétrico de vidro temperado de $45 \mathrm{kN}$ utilizado nas experiências, cujo diâmetro maior foi de $166 \mathrm{~mm}$, altura de $77 \mathrm{~mm}$ e peso de $960 \mathrm{~g}$.

Tabela 1: Composição química do vidro de silicato sodo-cálcico (\% em massa).

\begin{tabular}{c|c|c|c|c|c|c|c|c}
\hline $\mathrm{SiO}_{2}$ & $\mathrm{Na}_{2} \mathrm{O}$ & $\mathrm{CaO}$ & $\mathrm{Al}_{2} \mathrm{O}_{3}$ & $\mathrm{BaO}$ & $\mathrm{K}_{2} \mathrm{O}$ & $\mathrm{Sb}_{2} \mathrm{O}_{3}$ & $\mathrm{MgO}$ & $\mathrm{Fe}_{2} \mathrm{O}_{3}$ \\
\hline 71,85 & 14,06 & 9,20 & 2,00 & 1,30 & 1,00 & 0,55 & 0,02 & 0,02 \\
\hline
\end{tabular}

A produção do dielétrico de vidro temperado foi realizada por uma rota de processamento industrial (Prismatic, Sorocaba, SP) envolvendo as seguintes etapas:

a) Fusão e afinagem: as matérias-primas foram fundidas a $1500^{\circ} \mathrm{C}$ em um forno tipo work end de capacidade de 6 t/dia por um período suficiente para a eliminação das bolhas de gases do banho de vidro (afinagem). Em seguida, o vidro foi transferido para a zona de trabalho do forno para homogeneização e resfriamento do banho até a temperatura de $1190^{\circ} \mathrm{C}$;

b) Conformação: um robô com uma colha na extremidade do braço de alimentação coletou uma "gota" de vidro fundido da zona de trabalho do forno de fusão (massa de 960 g) e transferiu-a para o molde de conformação. A conformação do dielétrico foi dividida em duas etapas: i) prensagem da gota fundida no molde para definição do perfil externo da peça, realizada com pressão de 3,9 MPa por um período de 9,5 s com o macho e o anel pré-aquecidos a 400 e $380^{\circ} \mathrm{C}$, respectivamente; e ii) conformação da ranhura interna da peça a $700^{\circ} \mathrm{C}$. A peça foi desmoldada a $690^{\circ} \mathrm{C}$ e o tempo total do processo de conformação foi de 79 s;

c) Homogeneização de temperatura: logo após a desmoldagem, a peça conformada foi transportada para uma estufa pré-aquecida a $580^{\circ} \mathrm{C}$ e mantida por $180 \mathrm{~s}$ para a homogeneização da temperatura;

d) Têmpera térmica: o dielétrico retirado da estufa de homogeneização a $580^{\circ} \mathrm{C}$ foi transferido para o dispositivo de têmpera (tournettes), no qual a peça foi rotacionada a $500 \mathrm{rpm}$ enquanto jatos de ar 
comprimido com pressão de 0,25 $\mathrm{MPa}$ foram direcionados sobre a peça (Figura 2), causando um resfriamento brusco de aproximadamente $300^{\circ} \mathrm{C}$ em um tempo aproximado de $50 \mathrm{~s}$;

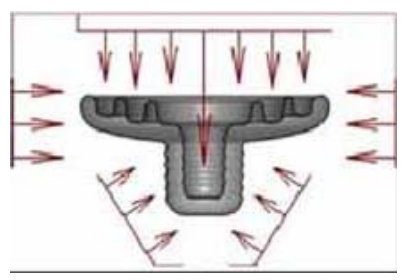

Figura 2: Esquema dos fluxos de ar sobre o dielétrico no dispositivo de têmpera - tournettes.

e) Resfriamento controlado pós têmpera: depois de retirada do dispositivo de têmpera, a peça foi colocada em um forno contínuo de esteira metálica ("lehr”) em um ciclo de resfriamento controlado para minimizar as quebras por tensões residuais. O forno possuía seis zonas de temperaturas, sendo que as duas primeiras zonas trabalharam a $350^{\circ} \mathrm{C}$, as duas intermediárias a cerca de $300^{\circ} \mathrm{C}$ e as duas últimas a $250^{\circ} \mathrm{C}$. $\mathrm{O}$ tempo total de resfriamento controlado pós-têmpera (tempo de permanência da peça no forno) foi de 80 min;

f) Choque térmico: a peça, após a passagem pelo forno lehr, estava a aproximadamente $240^{\circ} \mathrm{C}$ no momento em que foi mergulhada em água a uma temperatura de $60^{\circ} \mathrm{C}$, resultando assim em um choque térmico com diferença de temperatura, $\Delta \mathrm{T}$, de $180^{\circ} \mathrm{C}$, que teve função de eliminar peças não temperadas corretamente. As peças que sobreviveram ao primeiro choque térmico foram reaquecidas a $120^{\circ} \mathrm{C}$ e mergulhadas novamente em água a $60^{\circ} \mathrm{C}$, resultando assim em um segundo choque térmico com $\Delta \mathrm{T}$ de $60^{\circ} \mathrm{C}$. Estes tratamentos de choque térmico têm sido empregados industrialmente para eliminar os dielétricos que apresentam fragilidade relacionada aos defeitos de processamento;

g) Têmpera química: foi realizado um tratamento de têmpera química curto, em banho de $\mathrm{KNO}_{3}$ a $450^{\circ} \mathrm{C}$ por $30 \mathrm{~min}$, para troca iônica entre o $\mathrm{K}^{+}$do banho e o $\mathrm{Na}^{+}$do vidro. Após resfriamento no banho de sal até $60^{\circ} \mathrm{C}$, os dielétricos foram lavados com água, também a $60^{\circ} \mathrm{C}$, para a eliminação do excesso de sais impregnados no produto e evitar ocorrência de fosqueamento. A Figura 3 apresenta o fluxograma do processo de produção do dielétrico de vidro temperado em dois estágios.

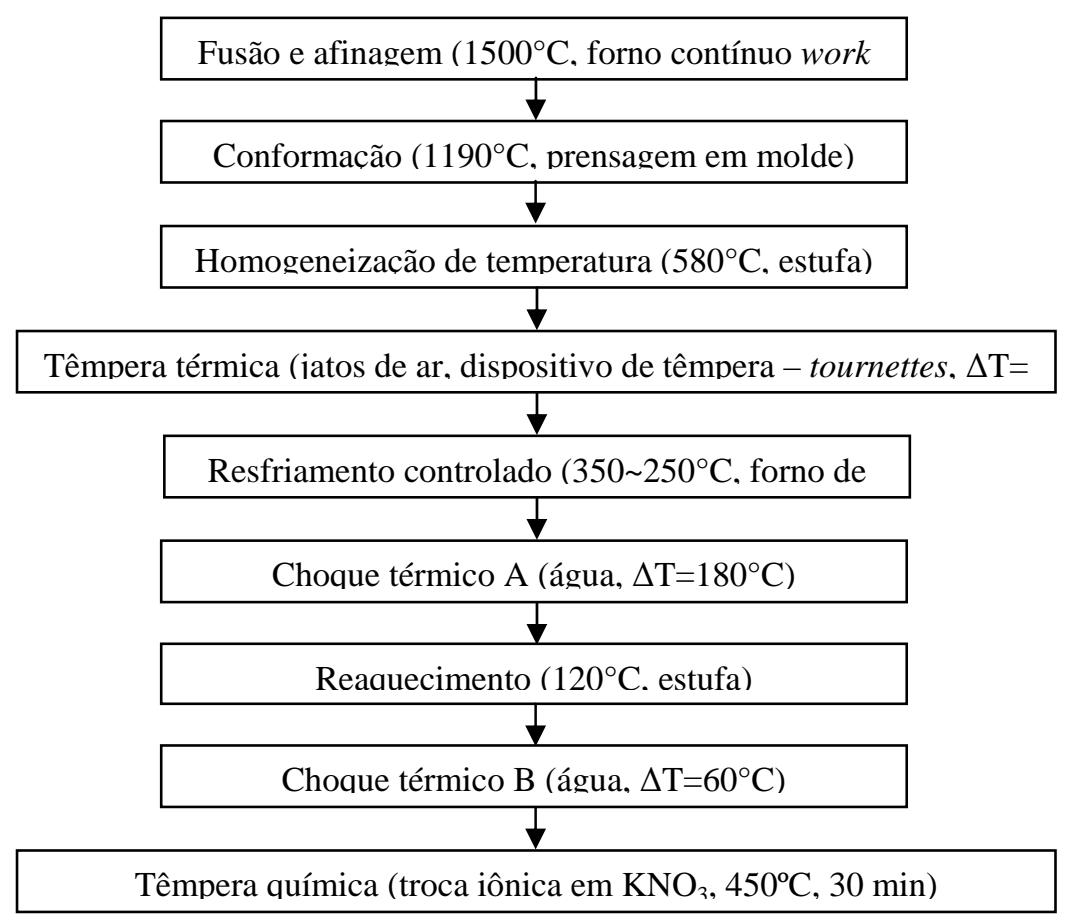

Figura 3: Etapas do processo de produção do dielétrico de vidro temperado em dois estágios, têmpera térmica seguida de troca iônica.

Foram preparados três conjuntos de peças conforme o processo de têmpera: 
i) têmpera térmica - TT;

ii) têmpera química - TQ; e

iii) têmpera de dois estágios - TT+TQ.

No caso do conjunto somente temperado quimicamente, TQ, as peças após conformação foram submetidas ao ciclo de recozimento no forno lehr e, então, submetidas à etapa de troca iônica. O conjunto TQ foi preparado principalmente para se compreender o efeito do segundo estágio no tratamento de têmpera de dois estágios.

Uma amostra do vidro empregado na produção do dielétrico foi submetida à análise térmica diferencial, ATD (Netzsch, modelo 404), para determinação da temperatura de transição vítrea, $\mathrm{T}_{\mathrm{g}}$, utilizando uma taxa de aquecimento de $10^{\circ} \mathrm{C} / \mathrm{min}$ até $800^{\circ} \mathrm{C}$. Os dielétricos produzidos foram caracterizados por meio de ensaios mecânicos (compressão e impacto) e ensaios termomecânicos (choque térmico no aquecimento, no resfriamento e na ciclagem térmica), conforme metodologias usualmente empregadas na caracterização de dielétricos de vidro temperado [2]:

a) ensaio de compressão: a força de ruptura em compressão foi determinada em uma máquina universal de ensaios mecânicos (Emic, DL 60.000) com taxa de carregamento de $2 \mathrm{kN} / \mathrm{s}$;

b) ensaio de impacto: a energia absorvida no impacto foi determinada em um dispositivo com guia de massa tubular com escala de $2 \mathrm{~m}$, onde uma esfera de aço com massa de 0,5 kg foi posicionada em uma determinada altura sobre o dielétrico e deixada cair em queda livre no centro da peça; iniciou-se o ensaio com a esfera de aço posicionada a uma altura equivalente a $1 \mathrm{~J}$ de energia potencial e repetiu-se a operação na mesma peça elevando a altura da escala no intervalo equivalente a $1 \mathrm{~J}$ até a ruptura do dielétrico;

c) ensaio de choque térmico frio-quente (aquecimento): o tempo de ruptura neste ensaio foi determinado aquecendo-se rapidamente o dielétrico a partir da temperatura ambiente, $25 \pm 5^{\circ} \mathrm{C}$, até $370 \pm 10^{\circ} \mathrm{C}$ (em forno a gás) e mantendo-o nesta temperatura até a fratura, sendo que o tempo até a fratura foi medido com um cronômetro digital;

d) ensaio de choque térmico quente-frio (resfriamento): a fração dos corpos-de-prova que sobreviveram a este ensaio foi determinada aquecendo-se lentamente o dielétrico em uma estufa ventilada até a temperatura de $125 \pm 5^{\circ} \mathrm{C}$ e, em seguida, imergindo-o em água a uma temperatura de $15 \pm 5^{\circ} \mathrm{C}$ para resfriamento brusco;

e) ensaio de choque térmico por ciclagem térmica: o número de ciclos suportado pelo dielétrico neste ensaio foi determinado imergindo a peça em água quente a uma temperatura de $95 \pm 5^{\circ} \mathrm{C}$ por um tempo de 15 min e em seguida imergindo-a em água fria a uma temperatura de $5 \pm 5^{\circ} \mathrm{C}$ também por um tempo de $15 \mathrm{mim}$, tendo sido repetido este ciclo 10 vezes ou até a fratura do dielétrico.

Em cada condição de ensaio, foram analisados pelo menos vinte corpos-de-prova. A quantidade total de peças preparadas neste trabalho foi acima de 300. A análise estatística dos resultados foi realizada pelo método "t de Student" com nível de confiança de 95\%. As barras de erro apresentadas nos gráficos na próxima seção representam \pm um desvio-padrão. Parte dos resultados também foi analisada por meio da estatística de Weibull para determinação dos dois parâmetros de distribuição: o módulo de Weibull, $m$, e o valor característico, $X_{0}$. A equação que representa a distribuição de Weibull é dada por:

$$
P_{f}=1-\exp \left[1-\left(X / X_{0}\right)^{m}\right]
$$

onde, X representa o valor da força de ruptura em compressão ou tempo de ruptura em choque térmico frioquente e $\mathrm{P}_{\mathrm{f}}$ é a probabilidade de fratura, que foi calculada por:

$$
P_{f}=(i-0,5) / N
$$

onde, i é o número de ordem da força ou do tempo de ruptura e $\mathrm{N}$ é o número total de valores. O módulo m está inversamente relacionado com a dispersão dos resultados e o valor característico $\left(\mathrm{X}_{0}\right)$ é definido como o valor no qual a probabilidade de ocorrer a fratura do corpo-de-prova é de 63,3\%. Neste valor a probabilidade de fratura $\mathrm{P}_{\mathrm{f}}$ independe de $\mathrm{m}$, pois $\mathrm{X}=\mathrm{X}_{0}$ na Equação 1 .

\section{RESULTADOS E DISCUSSÃO}

A temperatura de transição vítrea, $\mathrm{T}_{\mathrm{g}}$, do vidro utilizado, determinada pela análise térmica diferencial realizada na taxa de aquecimento de $10^{\circ} \mathrm{C} / \mathrm{min}$, foi de $560^{\circ} \mathrm{C}$ (Figura 4). $\mathrm{O}$ valor da $\mathrm{T}_{\mathrm{g}}$ pode variar com o método de ensaio, taxa de aquecimento/resfriamento, composição química e teor de água dissolvida no 
vidro. Birtch e Shelby [26] observaram diminuição linear da $\mathrm{T}_{\mathrm{g}}$ com o aumento do teor de água em um vidro de silicato sodo-cálcico plano (float) comercial, tendo o valor da $\mathrm{T}_{\mathrm{g}}$ variado na faixa de $\sim 570$ a $545^{\circ} \mathrm{C}$, quando o teor de água foi variado entre $\sim 100$ e 1200 ppm em peso. Shelby et al. [27] determinaram valores da $\mathrm{T}_{\mathrm{g}}$ na faixa de 509 a $623^{\circ} \mathrm{C}$ em vidros experimentais de silicato sodo-cálcicos com diferentes teores de $\mathrm{SiO}_{2}, \mathrm{Na}_{2} \mathrm{O}, \mathrm{CaO}, \mathrm{MgO}, \mathrm{K}_{2} \mathrm{O}, \mathrm{Al}_{2} \mathrm{O}_{3}$ e $\mathrm{Li}_{2} \mathrm{O}$, cujas composições foram baseadas em vidros de recipientes comerciais. $\mathrm{O}$ valor determinado de $\mathrm{T}_{\mathrm{g}}$ de $560^{\circ} \mathrm{C}$ (Figura 4) no vidro utilizado na produção dos dielétricos (Tabela 1) foi, portanto, próximo dos valores reportados em literatura para vidros de silicato sodo-cálcicos.

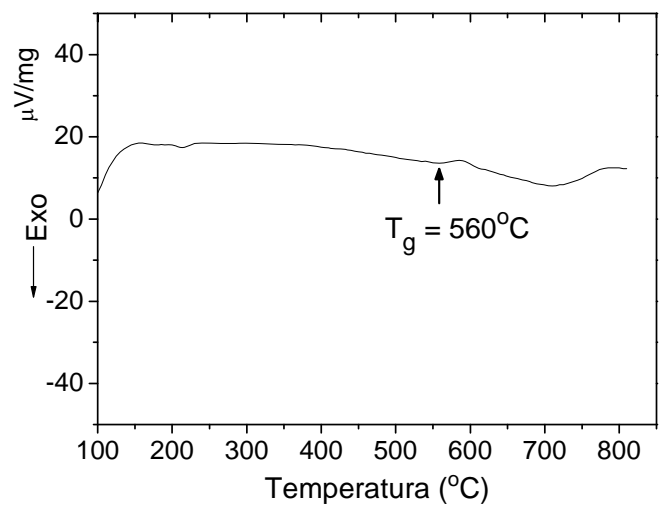

Figura 4: Curva de análise térmica diferencial, ATD, do vidro de silicato sodo-cáustico utilizado para a produção dos dielétricos.

\subsection{Propriedades mecânicas}

Os resultados dos ensaios de compressão e impacto tiveram tendências parecidas com o tipo de tratamento de têmpera empregado (Figura 5). O dielétrico temperado quimicamente (TQ) apresentou valores de força de ruptura em compressão, $\mathrm{F}_{\mathrm{r}}$ (Figura 5a), e energia absorvida no impacto, $\mathrm{E}_{\mathrm{abs}}$ (Figura 5b), significativamente menores do que os respectivos valores dos dielétricos temperados termicamente (TT) e em dois estágios (TT+TQ). O dielétrico TQ apresentou valores de $\mathrm{F}_{\mathrm{r}}$ e $\mathrm{E}_{\mathrm{abs}}$ de somente $46 \%$ e $69 \%$ dos respectivos valores do dielétrico TT, mostrando que o curto tratamento de têmpera química empregado não resultou em aumento significativo das propriedades mecânicas no nível de aumento causado pelo tratamento de têmpera térmica, inviabilizando-o para aplicação em isoladores de $45 \mathrm{kN}$, cujos valores mínimos especificados industrialmente são $F_{r}=150 \mathrm{kN}$ e $E_{a b s}=7 \mathrm{~J}$ [28]. O aumento nas propriedades mecânicas do dielétrico TQ causado pela troca iônica, entretanto, não foi desprezível, pois os 5,1 J de $\mathrm{E}_{\mathrm{abs}}$ é um valor considerável tomando-se como base as especificações gerais para vidro, que são de 0,2 J para vidros recozidos e de 1 a $5 \mathrm{~J}$ para vidros temperados [2]. Assim, embora o tempo de tratamento de têmpera química empregado tenha sido curto $\left(30 \mathrm{~min}\right.$ a $\left.450^{\circ} \mathrm{C}\right)$, é de se esperar que tenha ocorrido efetiva troca iônica entre os íons $\mathrm{Na}^{+}$do vidro por íons $\mathrm{K}^{+}$do banho de sal, o que resultou na formação de uma camada compressiva e no aumento das propriedades mecânicas do dielétrico, em comparação com o seu estado recozido. A forte influência de tratamentos de troca iônica realizados em tempos curtos na resistência mecânica de materiais vítreos tem sido reportada na literatura. Rosa [29] observou em uma porcelana feldspática para aplicação em prótese dentária, consistindo de uma matriz de vidro alumino-silicato $\left(\mathrm{T}_{\mathrm{g}}=575^{\circ} \mathrm{C}\right)$ com dispersão de partículas de leucita $\left(\mathrm{KAlSi}_{2} \mathrm{O}_{6}\right)$, um significativo aumento da resistência à flexão (cerca de 100\%), quando temperada quimicamente em $\mathrm{KNO}_{3}$ entre 450 e $490^{\circ} \mathrm{C}$ por apenas $15 \mathrm{~min}$.

Os resultados de $\mathrm{F}_{\mathrm{r}}$ (Figura $5 \mathrm{a}$ ) e $\mathrm{E}_{\mathrm{abs}}$ (Figura $5 \mathrm{~b}$ ) do dielétrico temperado em dois estágios (TT+TQ) foram estatisticamente semelhantes, no nível de confiança de 95\%, aos do dielétrico temperado termicamente (TT), mostrando que: i) a aplicação do segundo estágio de troca iônica, após o tratamento de têmpera térmica, não causou variação significativa das propriedades mecânicas; e ii) as propriedades mecânicas do dielétrico TT+TQ foram definidas principalmente no primeiro estágio de têmpera térmica. Nas condições em que foi realizada a troca iônica $\left(\mathrm{KNO}_{3}\right.$ por $30 \mathrm{~min}$ a $450^{\circ} \mathrm{C}$, que em temperatura absoluta é $\sim 87 \%$ da temperatura $\mathrm{T}_{\mathrm{g}}$ de $560^{\circ} \mathrm{C}$, Figura 4), é de se esperar que tenha ocorrido relaxação parcial das tensões residuais introduzidas no primeiro estágio de têmpera térmica. A relaxação de tensão em um vidro pode ser descrita pela seguinte equação [푸]:

$$
\sigma(t)=\sigma_{0} \exp (-t / \tau)
$$


onde, $\sigma(\mathrm{t})$ é a tensão dependente do tempo t, $\sigma_{0}$ é a tensão no tempo $\mathrm{t}=0$ e $\tau$ é o tempo de relaxação, que é proporcional à viscosidade, $\eta$, do vidro. Segundo simulação de McMaster et al. [8], a relaxação de tensão esperada em um vidro plano (float), com temperatura de recozimento superior (annealing point) de $540^{\circ} \mathrm{C}$, é de cerca de $20 \%$, quando aquecido a $450^{\circ} \mathrm{C}$ por $30 \mathrm{~min}$. Assim, supondo apenas a ocorrência do efeito da relaxação de tensão, seria de se esperar diminuição das propriedades mecânicas do dielétrico TT+TQ em relação ao dielétrico TT, o que não foi observado (Figuras 5a e 5b). Os resultados, portanto, sugerem que o efeito do estufamento iônico causado pela troca iônica resultou no aumento da resistência mecânica do dielétrico, compensando o efeito de diminuição de tensão causada pela relaxação de tensão.
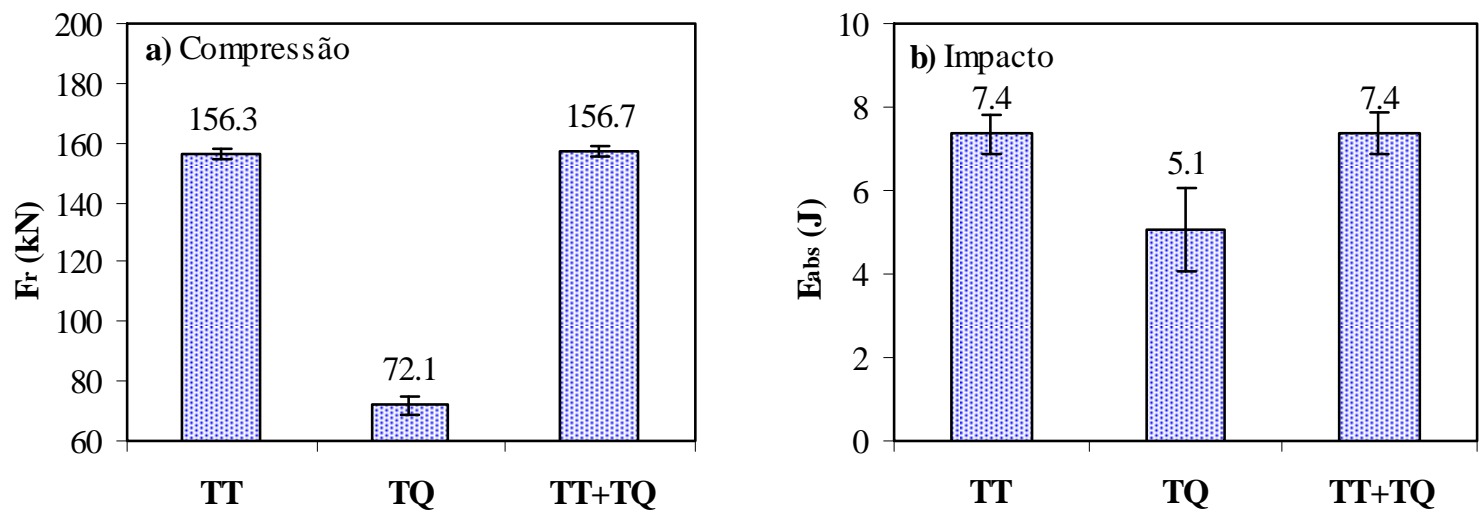

Figura 5: Resultados de força de ruptura no ensaio de compressão, $\mathrm{F}_{\mathrm{r}}(\mathrm{a})$, e energia absorvida no ensaio de impacto, $\mathrm{E}_{\mathrm{abs}}$ (b), dos dielétricos submetidos aos tratamentos de têmpera térmica (TT), têmpera química (TQ) e têmpera de dois estágios (TT+TQ).

A Figura 6 apresenta os gráficos de Weibull dos resultados de força de ruptura medidos no ensaio de compressão e a Tabela 2 apresenta os valores determinados dos parâmetros de distribuição de Weibull. Os valores do módulo de Weibull, $\mathrm{m}$, da força de ruptura dos dielétricos temperado termicamente (TT, m=91) e temperado em dois estágios $(\mathrm{TT}+\mathrm{TQ}, \mathrm{m}=104)$ foram significativamente maiores do que o do dielétrico temperado quimicamente $(\mathrm{TQ}, \mathrm{m}=30$ ). Os valores de $\mathrm{m}$ determinados foram elevados devido ao tipo de ensaio realizado (compressão) e às características de distribuição dos defeitos que resultaram na fratura do dielétrico, indicando elevada reprodutibilidade de produção principalmente dos dielétricos TT e TT+TQ. O segundo estágio de troca iônica no dielétrico TT+TQ, embora praticamente não tenha influenciado no valor de força de ruptura característica, $\mathrm{F}_{\mathrm{r}, 0}$, resultou em aumento de 14,3\% no módulo de Weibull, m, em relação ao do dielétrico TT (Tabela 2). As curvas de distribuição de Weibull destes dielétricos mostraram que a troca iônica, realizada após a têmpera térmica, teve o efeito de aumentar principalmente a força de ruptura das peças mais fracas do conjunto, resultando em aumento do valor de m (Figura 6b).

Tabela 2: Parâmetros de Weibull ( $\mathrm{F}_{\mathrm{r}, 0}$ - força de ruptura característica e $\mathrm{m}$ - módulo de Weibull) e coeficiente de correlação $\left(\mathrm{R}^{2}\right)$ da curva ajustada nos valores de força de ruptura em compressão.

\begin{tabular}{c|c|c|c}
\hline Processo & $\mathrm{F}_{\mathrm{r}, 0}(\mathrm{kN})$ & $\mathrm{m}$ & $\mathrm{R}^{2}$ \\
\hline TT & 157 & 91 & 0,965 \\
TQ & 73 & 30 & 0,958 \\
TT+TQ & 158 & 104 & 0,888 \\
\hline
\end{tabular}

A aplicação do tratamento de têmpera química pode resultar no aumento da dispersão dos valores de tensão de fratura, isto é, na diminuição do módulo de Weibull, m, dependendo da distribuição dos tamanhos dos defeitos superficiais na peça e da profundidade de têmpera (troca iônica), que é função da temperatura,

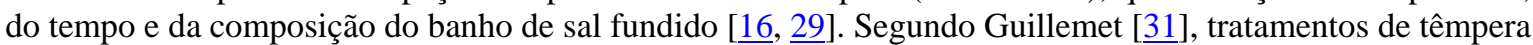
química de curto período têm sido experimentados para o reforço dos vidros de silicato sodo-cálcicos para embalagens, que resultam em pequenas profundidades de camada de troca iônica (10 a $20 \mu \mathrm{m})$. A pequena profundidade da camada de tensão residual de compressão possibilita o reforço das peças com os menores defeitos superficiais, isto é, as peças que originariamente apresentam os maiores valores de tensão de fratura (antes do tratamento de têmpera), enquanto as peças mais fracas do conjunto, com defeitos profundos, tendem a ser menos beneficiadas pela troca iônica, o que aumenta a dispersão dos resultados e diminui a 
confiabilidade mecânica do produto. Assim, o valor relativamente baixo de módulo de Weibull, m, do dielétrico temperado quimicamente (TQ, Figura 6a) parece estar relacionado com a pequena profundidade de troca iônica resultante do curto tempo de tratamento de têmpera química empregado. A troca iônica aplicada após a têmpera térmica, entretanto, resultou em efeito oposto ao da aplicação somente de troca iônica, tendo fortalecido principalmente as peças mais fracas do conjunto (Figura 6b), indicando um efeito sinérgico do tratamento de têmpera química com o tratamento de têmpera térmica.
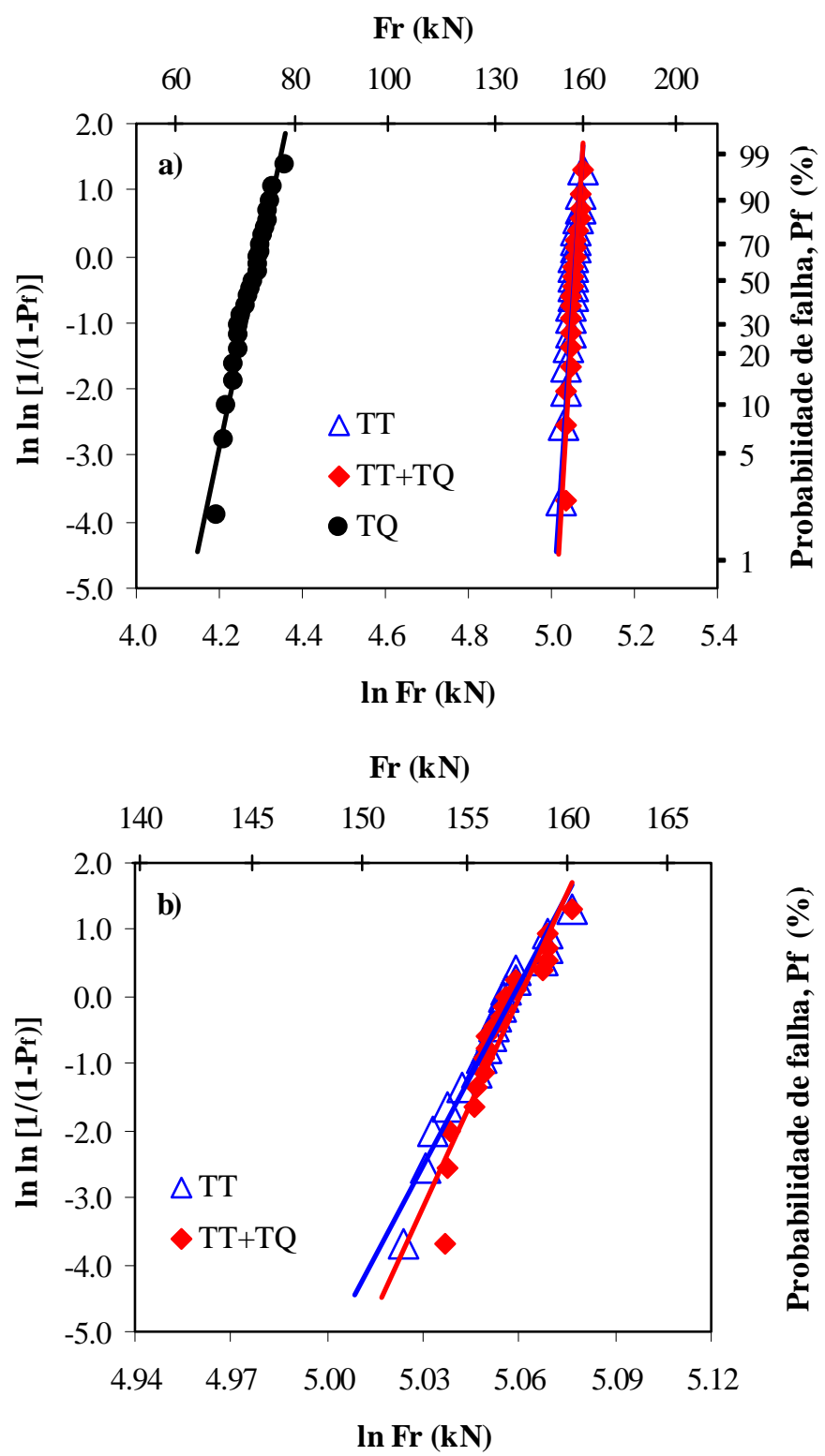

Figura 6: Gráficos de Weibull dos valores de força de ruptura em compressão, $\mathrm{F}_{\mathrm{r}}$, dos dielétricos submetidos aos tratamentos de têmpera térmica (TT), têmpera química (TQ) e têmpera de dois estágios (TT+TQ).

\subsection{Propriedades termomecânicas}

Os resultados dos ensaios de choque térmico quente-frio (aquecimento), frio-quente (resfriamento) e ciclagem térmica estão apresentados na Figura 7. As tendências dos resultados dos ensaios de choque térmico, em função do tipo de tratamento de têmpera empregado, foram diferentes daquelas observadas nas propriedades mecânicas (Figura 5). No ensaio choque térmico frio-quente, o dielétrico foi aquecido rapidamente a partir da temperatura ambiente até $370^{\circ} \mathrm{C}\left(\Delta \mathrm{T}=-345^{\circ} \mathrm{C}\right)$ e mantidos nesta temperatura até a fratura. $\mathrm{O}$ tempo de ruptura, $\mathrm{t}_{\mathrm{r}}$, após aquecimento brusco do dielétrico temperado em dois estágios (TT+TQ) foi significativamente maior, no nível de confiança de $95 \%$, do que os valores dos dielétricos temperado termicamente (TT) e temperado quimicamente (TQ), cujos valores foram estatisticamente semelhantes entre si (Figura 7a). O aumento do valor médio de $\mathrm{t}_{\mathrm{r}}$ observado no dielétrico TT+TQ foi de 5,6\% em relação ao do 
dielétrico TT. O dielétrico TT+TQ também apresentou desempenhos superiores aos do dielétrico TT nos ensaios de choque térmico quente-frio e ciclagem térmica (Figura 7b), sendo que o dielétrico TT apresentou parte dos corpos-de-prova (10 a $15 \%)$ que não suportou o resfriamento brusco $\left(\Delta \mathrm{T}=+110^{\circ} \mathrm{C}\right)$ ou a ciclagem térmica $\left(\Delta \mathrm{T}= \pm 90^{\circ} \mathrm{C} \times 10\right.$ ciclos), enquanto todos os corpos-de-prova dos dielétricos TQ e TT+TQ sobreviveram a estas condições de choque térmico (Figura 7b). Os resultados mostraram, portanto, que o segundo estágio de troca iônica no dielétrico TT+TQ resultou em aumento significativo de resistência ao choque térmico (no aquecimento, no resfriamento e na ciclagem térmica), em relação ao dielétrico somente temperado termicamente (TT).
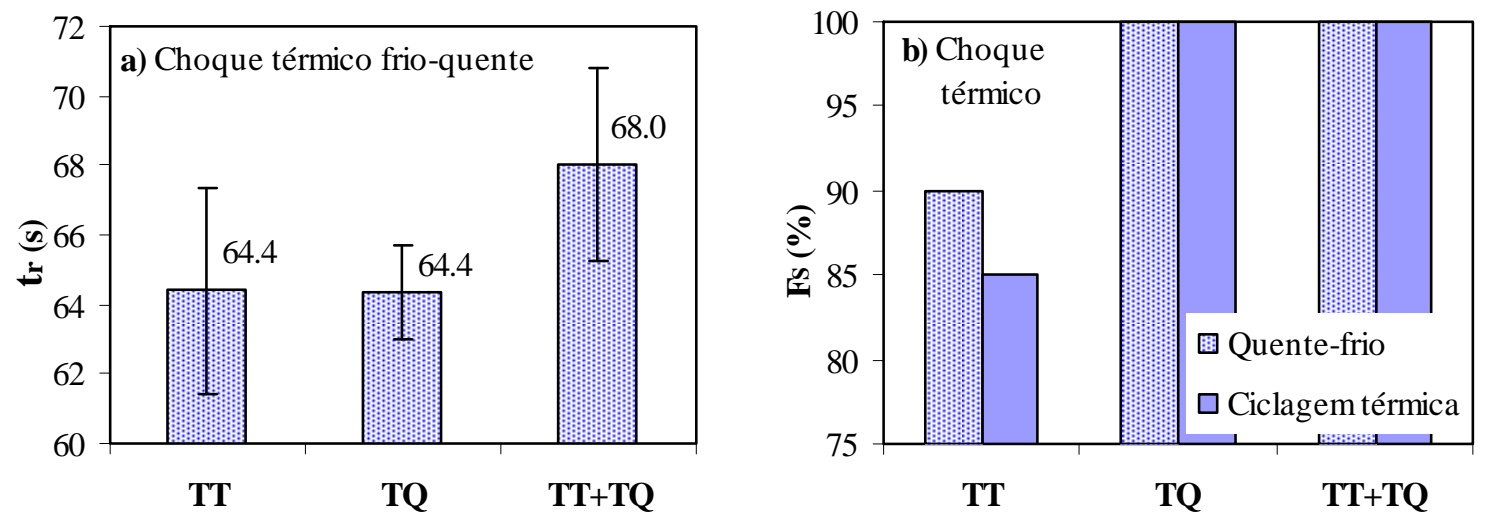

Figura 7: Resultados de tempo de ruptura no ensaio de choque térmico frio-quente, $\mathrm{t}_{\mathrm{r}}(\mathrm{a})$, e fração de peças que suportaram os ensaios de choque térmico quente-frio e ciclagem térmica, $\mathrm{F}_{\mathrm{S}}(\mathrm{b})$, dos dielétricos tratados por têmpera térmica (TT), têmpera química (TQ) e têmpera de dois estágios (TT+TQ).

O dielétrico temperado quimicamente (TQ) apresentou desempenhos superiores aos do dielétrico TT nos ensaios de resfriamento brusco e ciclagem térmica (Figura 7b) e, também, menor desvio-padrão no valor de tempo de ruptura, $t_{r}$, no ensaio de aquecimento brusco (Figura 7a). Os bons resultados do dielétrico TQ nos ensaios de choque térmico foram surpreendentes, uma vez que a sua resistência mecânica (indicada pela força de ruptura em compressão, Figura 5a) foi significativamente menor do que a do dielétrico TT. O parâmetro de resistência ao choque térmico R', associado à condição de iniciação da fratura quando a tensão térmica alcança a tensão de ruptura do material, prevê relação direta entre a resistência à ruptura $\left(\sigma_{\mathrm{f}}\right)$ e a resistência ao choque térmico de um material frágil, conforme [32]:

$$
R^{\prime}=\frac{k \sigma_{f}(1-v)}{E \alpha}
$$

onde, $\mathrm{k}$ é a condutividade térmica, $v$ é o coeficiente de Poisson, E é o módulo de elasticidade e $\alpha$ é o coeficiente de expansão térmica do material. O parâmetro R' também não explica os desempenhos superiores nos ensaios de choque térmico observados no dielétrico TT+TQ em relação ao dielétrico TT, uma vez que as propriedades mecânicas foram semelhantes nos dois materiais (Figura 5).

A Figura 8 apresenta os gráficos de Weibull dos resultados de tempo de ruptura medidos no ensaio de choque térmico frio-quente e a Tabela 3 apresenta os valores determinados dos parâmetros de distribuição de Weibull. Os valores de módulo de Weibull, $\mathrm{m}$, do tempo de ruptura no ensaio de choque térmico dos dielétricos TT e TT+TQ foram significativamente menores (menos de 1/3, Tabela 3) do que os valores de $\mathrm{m}$ da força de ruptura em compressão (Tabela 2), indicando que os defeitos que limitaram os desempenhos nos dois ensaios apresentaram características diferentes. Não foi possível identificar as origens das fraturas nos dois ensaios, uma vez que a ruptura dos dielétricos apresentou intensa fragmentação em decorrência da elevada energia elástica armazenada, como usualmente é observada em vidros temperados. Entretanto, é razoável supor que as evoluções das tensões transientes durante as solicitações mecânicas e termomecânicas tenham sido diferentes ao longo do dielétrico, o que deve ter resultado em diferentes regiões com máxima tensão transiente. Além disso, devido à complexidade da geometria do dielétrico (Figura 1) e da rota de processamento (Figura 3), é de se esperar que diferentes regiões da peça tenham apresentado diferentes populações de defeitos. 
Tempo de ruptura em choque térmico quente-frio

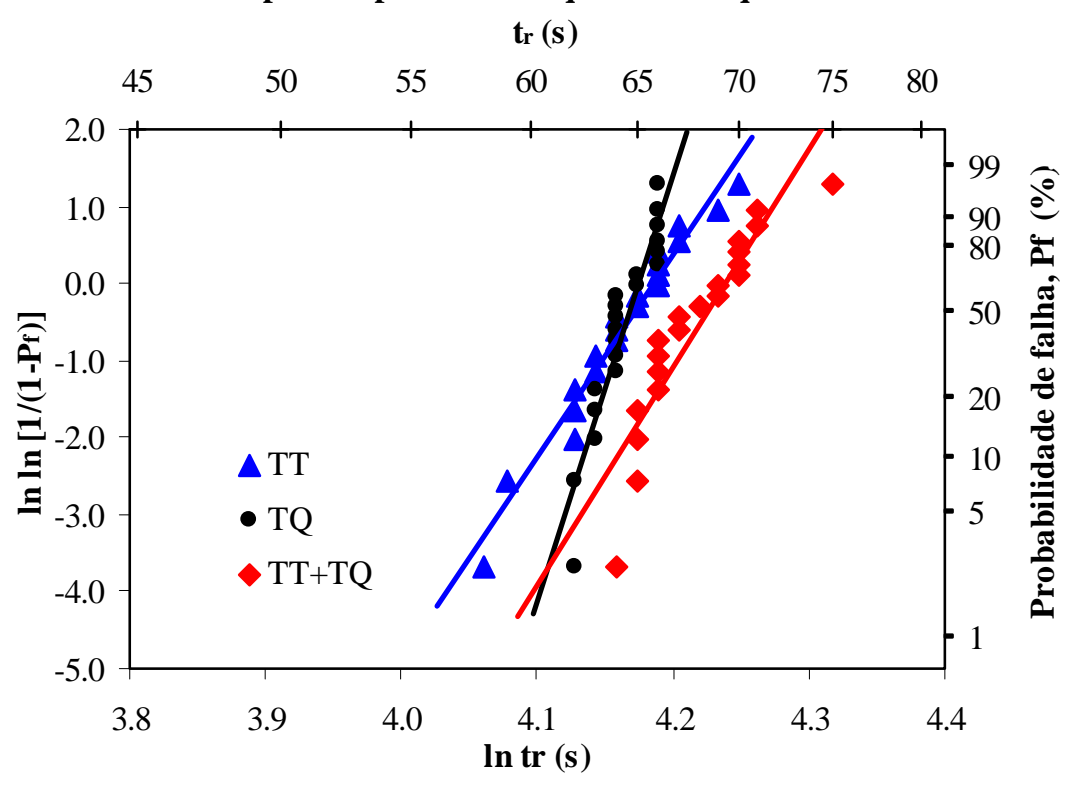

Figura 8: Gráficos de Weibull dos valores de tempo de ruptura em compressão, $\mathrm{t}_{\mathrm{r}}$, dos dielétricos submetidos aos tratamentos de têmpera térmica (TT), têmpera química (TQ) e têmpera de dois estágios (TT+TQ).

Tabela 3: Parâmetros de Weibull ( $\mathrm{t}_{\mathrm{r}, 0}$ - tempo de ruptura característico e $\mathrm{m}$ - módulo de Weibull) e coeficiente de correlação $\left(\mathrm{R}^{2}\right)$ da curva ajustada nos valores de tempo de ruptura no ensaio de choque térmico frio-quente.

\begin{tabular}{c|c|c|c}
\hline Processo & $\mathrm{t}_{\mathrm{r}, 0}(\mathrm{~s})$ & $\mathrm{m}$ & $\mathrm{R}^{2}$ \\
\hline TT & 66 & 26 & 0,965 \\
TQ & 65 & 56 & 0,885 \\
TT+TQ & 69 & 28 & 0,836 \\
\hline
\end{tabular}

Os defeitos que limitam o desempenho do dielétrico de vidro usualmente são microtrincas superficiais geradas durante o processamento. Guedes [2] sugeriu que microtrincas são geradas ou crescidas na superfície do dielétrico principalmente durante a desmoldagem do dielétrico na etapa de conformação, causadas pelo resfriamento brusco devido à exposição da peça conformada quente ao ambiente, e/ou durante o resfriamento brusco na etapa de têmpera térmica, baseado na observação de ocorrência esporádica de fratura de peças nestas etapas, cuja freqüência dependeu dos parâmetros de processo empregados. O alto módulo de Weibull, $\mathrm{m}$, do tempo de ruptura no ensaio de choque térmico do dielétrico TQ ( $\mathrm{m}=56$, Tabela 3), que foi significativamente maior do que o valor de $m$ da força de ruptura em compressão ( $m=30$, Tabela 2), reforça a interpretação de que as fraturas nos ensaios de compressão e de choque térmico iniciaram em diferentes regiões com diferentes distribuições de defeitos (microtrincas). No caso do dielétrico TQ, as microtrincas superficiais possivelmente foram menos profundas na região onde se iniciou a fratura das peças no ensaio de choque térmico frio-quente do que na região onde se iniciou a fratura no ensaio de compressão, o que propiciou o reforço, pela camada compressiva introduzida pela troca iônica, da maioria das peças do conjunto, resultando em elevada confiabilidade termomecânica. Como a rota de processamento do dielétrico TQ não envolveu a etapa de têmpera térmica, provavelmente os defeitos que limitaram o tempo de ruptura no ensaio de choque térmico de aquecimento deste dielétrico (TQ) foram microtrincas introduzidas durante a etapa de conformação. Já no caso dos dielétricos TT e TT+TQ, os menores valores de m do tempo de ruptura no ensaio de choque térmico (Tabela 3) indicaram que estes materiais apresentaram distribuições de tamanho de microtrincas mais largas do que a do dielétrico TQ, sugerindo que a etapa de têmpera térmica causou o crescimento de microtrincas introduzidas na etapa de conformação e/ou a formação de novas microtrincas, levando a maiores variações dos resultados.

O segundo estágio de troca iônica teve um efeito de reforço significativo no desempenho termomecânico do dielétrico TT+TQ, tendo causado aumento de 7,7\% no módulo de Weibull, m, e de 5,5\% no tempo de ruptura característico, $\mathrm{t}_{\mathrm{r}, 0}$, no ensaio de choque térmico de aquecimento, em relação ao dielétrico 
TT (Tabela 3). As curvas de distribuição de Weibull destes dielétricos mostraram que a troca iônica, realizada após a têmpera térmica, teve o efeito geral de aumentar o tempo de ruptura de todas as peças do conjunto, mas maiores aumentos foram observados nas peças mais fracas do conjunto (Figura 8), o que resultou no aumento da confiabilidade termomecânica (aumento do valor de m) do dielétrico TT+TQ. As distribuições de Weibull dos resultados de força de ruptura em compressão (Figura 6b) e do tempo de ruptura no ensaio de choque térmico de aquecimento (Figura 8) dos dielétricos TT e TT+TQ mostraram que o efeito comum da aplicação da troca iônica, após a têmpera térmica, foi o de reforçar as peças mais fracas do conjunto. Esta interpretação é reforçada pelos melhores desempenhos do dielétrico submetido ao tratamento de têmpera de dois estágios (TT+TQ) nos ensaios de choque térmico de resfriamento e por ciclagem térmica (maiores valores de fração de peças que suportaram os ensaios de choque térmico, $\mathrm{F}_{\mathrm{S}}$, Figura $7 \mathrm{~b}$ ), em relação às amostras somente temperadas termicamente (TT).

\subsection{Efeito da troca iônica após têmpera térmica}

O dielétrico produzido pelo processo de têmpera de dois estágios, com aplicação da troca iônica após a têmpera térmica (TT+TQ), apresentou as seguintes características, quando comparado ao dielétrico produzido convencionalmente por têmpera térmica:

a) manutenção da resistência mecânica (Figura 5);

b) aumento da resistência ao choque térmico (Figura 7); e

c) aumento da confiabilidade mecânica (Figura 6b) e termomecânica (Figura 8).

Os resultados acima mostraram que o processo de têmpera de dois estágios empregado neste trabalho (Figura 3) é viável para a produção de dielétricos de vidro temperado com elevada confiabilidade mecânica e termomecânica, sem prejuízo das propriedades mecânicas e de choque térmico. Embora diversos parâmetros sejam relevantes neste processo, como a composição química do vidro, os defeitos gerados no processamento do dielétrico e as condições de têmpera térmica, o segundo estágio (troca iônica) parece definir as características finais de comportamento mecânico e termomecânico do dielétrico. $\mathrm{O}$ efeito da troca iônica na evolução do perfil de tensão residual em peças previamente temperadas termicamente é mais complexo do que quando aplicada em peças recozidas, pois envolve a atuação simultânea de três fenômenos durante a têmpera química: i) geração de tensão induzida pelo estufamento iônico, decorrente da troca de íons; ii) relaxação do perfil de tensão residual introduzido pela têmpera térmica, decorrente do aquecimento na troca iônica; e iii) relaxação da tensão introduzida no próprio processo de troca iônica, causada pelo rearranjo dos íons na rede do vidro. A diminuição significativa de $11 \%$ da resistência mecânica observada por Anusavice et al. [25], devido à aplicação da troca iônica após a têmpera térmica em uma porcelana dentária, pode ser explicada pelo excesso de relaxação de tensão decorrente dos parâmetros empregados no segundo estágio (composição do banho de sal, temperatura e tempo de troca iônica), o que diminuiu significativamente a tensão residual de compressão introduzida pela têmpera térmica. A otimização do processo de têmpera de dois estágios para maximização das propriedades e confiabilidades mecânicas e termomecânicas, portanto, depende fortemente dos parâmetros da troca iônica.

Os aumentos da confiabilidade mecânica e termomecânica causados pela troca iônica, aplicada após a têmpera térmica, sugerem que o dielétrico temperado pelo método de dois estágios apresentou um perfil de tensão residual com um valor de máxima tensão de compressão deslocado a uma determinada profundidade da superfície, que dificultou o crescimento da trinca na região superficial por um comportamento equivalente ao de curva R crescente [1]-20]. Aparentemente não há informações relativas à evolução do perfil de tensão residual no tratamento de têmpera térmica seguida de troca iônica. Pode-se estimar, como primeira aproximação, o perfil de tensão residual da têmpera de dois estágios supondo que os efeitos de aumento de tensão residual de ambos os tratamentos de têmpera, térmica e química, sejam aditivos e que a relaxação de tensão ocorre sobre a tensão resultante. A Figura 9a apresenta um diagrama com curvas hipotéticas dos dielétricos submetidos à têmpera térmica, TT, têmpera química, TQ, e têmpera de dois estágios, TT+TQ, que foram traçadas com base nas seguintes considerações: a) curva TT: é parabólica, onde a tensão de compressão na superfície é o dobro da tensão de tração no centro do vidro []]; b) curva TQ: apresenta perfil com máxima tensão de compressão deslocada a certa distância da superfície, em decorrência da relaxação de tensão próxima à superfície, que tem sido observada tanto em tratamentos longos como curtos de troca iônica $[\underline{10}, \underline{17}]$, e o valor de máxima tensão residual de compressão da curva TQ é de $46 \%$ do valor da curva TT, conforme resultados de força de ruptura no ensaio de compressão (Figura 5a); e c) curva TT+TQ: foi calculada como a soma dos valores de tensão residual das curvas TT e TQ, reduzida pela relaxação de tensão, considerando que a taxa de relaxação é proporcional ao quadrado da tensão [12]. 


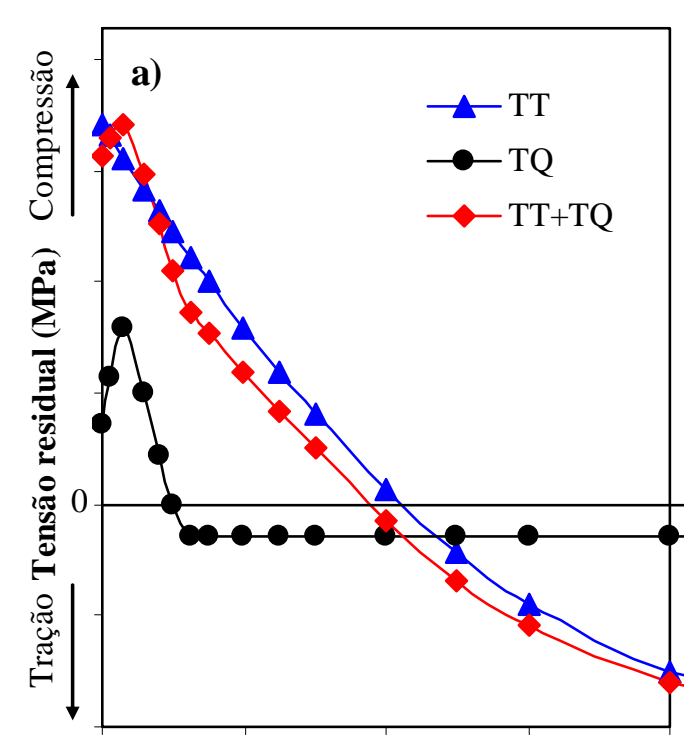

Distância da superfície (mm)

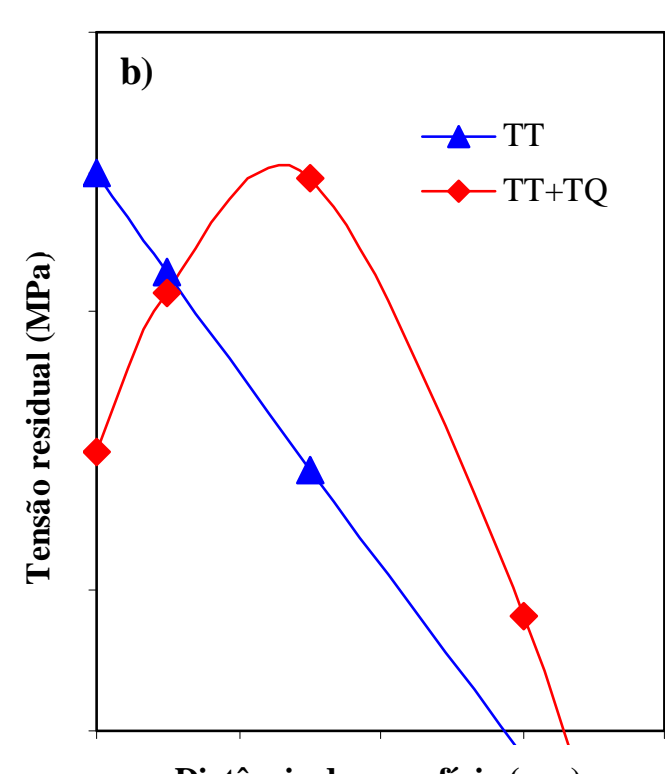

Distância da superfície (mm)

Figura 9: (a) Diagrama representando os possíveis perfis de tensão residual dos dielétricos tratados por têmpera térmica, TT, têmpera química, TQ, e têmpera de dois estágios, TT+TQ, e (b) detalhe do diagrama mostrando o perfil com máxima tensão residual de compressão deslocada a certa distância da superfície.

A curva TT+TQ estimada apresentou um perfil de tensão residual com máxima tensão de compressão deslocada a certa profundidade da superfície, com valor máximo similar ao da curva TT (Figura 9b), em conformidade com a interpretação de que a diminuição do nível de tensão introduzida pela têmpera térmica foi contrabalanceada pelo aumento de tensão causado pela troca iônica, resultando em valores similares de propriedades mecânicas nos dielétricos TT e TT+TQ (Figura 5). A abordagem acima é simplificada, pois não considera os possíveis efeitos interativos entre os dois processos de têmpera, como a mudança na cinética de troca de íons causada pela presença de um gradiente de tensão residual introduzida pela têmpera térmica e a alteração nos mecanismos envolvidos na relaxação de tensão resultante dos dois processos. Ainda assim, ela sugere que é possível se obter um perfil de tensão residual com máxima tensão de compressão deslocada da superfície, com manutenção do nível máximo de tensão residual de compressão, por meio do tratamento de têmpera de dois estágios, quando se aplica uma troca iônica após a têmpera térmica (Figura 9). Este método de têmpera de dois estágios apresenta vantagem em relação ao método proposto por Schaeffer [17] de aplicação de uma "têmpera térmica inversa” (aquecimento rápido) após a têmpera térmica para obtenção do perfil de tensão residual controlado, que resulta inevitavelmente na diminuição da máxima tensão de compressão e, portanto, da resistência mecânica.

O perfil de aumento da tensão residual de compressão até o máximo valor na região próxima à superfície dificulta a propagação da trinca devido ao efeito de aumento da tenacidade à fratura aparente com o crescimento da trinca [19]. A ocorrência deste comportamento (curva $\mathrm{R}$ crescente) não é prevista no critério de resistência ao choque térmico R' (Equação 4), o que parece explicar, ao menos em parte, a não correspondência entre os resultados de propriedades mecânicas (Figura 5) e de choque térmico (Figura 7) dos dielétricos temperados por diferentes métodos. O comportamento de curva $\mathrm{R}$ crescente possibilita o arresto do crescimento da trinca, o que propicia uma homogeneização do tamanho do defeito crítico para ocorrência da fratura e, portanto, na diminuição da dispersão dos valores de tensão de ruptura, com conseqüente aumento da confiabilidade mecânica e termomecânica do componente. O comportamento de curva R crescente também pode resultar em aumento de resistência mecânica, como tem sido observado nas cerâmicas contendo zircônia [33, $\underline{34}$ ]. De fato, Sglavo e Green [21] observaram aumentos de até 7,9\% na resistência à flexão de um vidro de alumino-silicato sódico tratado pelo método da troca iônica de dois estágios em comparação com o tratamento convencional de têmpera química. Neste trabalho, o vidro de silicato sodo-cálcico tratado pelo método de têmpera de dois estágios, têmpera térmica seguida de troca iônica, embora tenha apresentado valores das propriedades mecânicas similares (Figura 5), apresentou aumento de 5,6\% no tempo de ruptura no ensaio de choque térmico de aquecimento em comparação com o tratamento convencional de têmpera térmica (Figura 7a). Os resultados acima sugerem que a otimização dos parâmetros do estágio de troca iônica (composição do banho de sal, temperatura e tempo de tratamento) pode melhorar ainda mais as propriedades mecânicas e termomecânicas do dielétrico tratado por meio da têmpera de dois estágios. A presença de um perfil de tensão residual com máxima tensão de compressão deslocada a 
certa profundidade da superfície, o comportamento de curva R crescente e a possibilidade de melhorar ainda mais as propriedades, entretanto, precisam ainda ser confirmadas experimentalmente. Estudos para compreensão dos efeitos do gradiente de tensão residual, introduzida pela têmpera térmica, na cinética de troca iônica e dos mecanismos envolvidos na relaxação de tensão resultante dos dois estágios de têmpera, térmica e química, também precisam ser realizados para viabilizar o modelamento do processo de têmpera de dois estágios, o que poderá propiciar a previsibilidade do comportamento mecânico e termomecânico do dielétrico de vidro temperado por este método.

\section{CONCLUSÕES}

Neste trabalho mostrou-se que o método de têmpera de dois estágios, têmpera térmica seguida de troca iônica de curto período, é viável para a produção de dielétricos de vidro com elevadas propriedades e confiabilidades mecânicas e termomecânicas.

A aplicação do tratamento de troca iônica em $\mathrm{KNO}_{3}$ a $450^{\circ} \mathrm{C}$ por 30 min, após a têmpera térmica, em um dielétrico de vidro de silicato sodo-cáustico resultou em: i) manutenção das propriedades mecânicas (força de ruptura em compressão e energia absorvida no impacto) nos níveis alcançados na têmpera térmica; ii) aumento da resistência ao choque térmico (aumento de 5,6\% no tempo de ruptura no choque térmico de aquecimento e aumento da fração de peças que sobreviveram ao choque térmico de resfriamento e de ciclagem térmica); e iii) aumento dos valores de módulo de Weibull, m, da força de ruptura em compressão $(+14,3 \%)$ e do tempo de ruptura no choque térmico $(+7,7 \%)$.

No segundo estágio, o reforço causado pela troca iônica contrabalanceou o efeito da relaxação de tensão residual introduzida na têmpera térmica, mantendo as propriedades mecânicas elevadas. A troca iônica reforçou principalmente as peças mais fracas do conjunto, o que aumentou a confiabilidade (módulo de Weibull) mecânica e termomecânica do dielétrico.

Não foi possível correlacionar os resultados dos ensaios mecânicos e de choque térmico, como esperado pelo critério de tensão de resistência ao choque térmico, R', possivelmente devido à ocorrência de um comportamento de curva $\mathrm{R}$ crescente no dielétrico tratado pelo método de têmpera de dois estágios, como conseqüência da formação de um perfil de tensão residual com a máxima tensão de compressão deslocada a certa profundidade da superfície.

\section{AGRADECIMENTOS}

Os autores agradecem à empresa Prismatic, que possibilitou a realização deste trabalho. HNY também agradece ao CNPq pela Bolsa de Produtividade em Desenvolvimento Tecnológico e Extensão Inovadora - DT.

\section{BIBLIOGRAFIA}

[1] NIGRI, A.I., "Desempenho de isoladores de linhas de transmissão - ponto de vista da manutenção”, In: Anais do XV SNPTEE - Seminário Nacional de Produção e Transmissão de Energia Elétrica, pp. 15 (GLT/13), Foz do Iguaçu, Outubro 1999.

[2] GUEDES, S., Efeitos da têmpera térmica e química em um dielétrico de vidro, Dissertação de M.Sc., CENATEC/IPT, São Paulo, SP, Brasil, 2007.

[3] CASTILHA, R., FAESARELlA, A.S., VELAZQUEZ, N.D.M., "Estudo preliminar do aumento da resistência mecânica de isoladores de vidro via cristalização superficial”, In: Anais do X Encuentro Regional Latino Americano de La CIGRÉ - Conférence Iternationale des Grands Réseaux Électriques, pp. 1-4 (X/PI-15.2), Puerto Iguazu, Maio 2003.

[4] CAVENAGHI, J.M., Efeito da prensagem sobre as propriedades elétricas e microestruturais de um varistor de ZnO, Dissertação de M.Sc., Universidade São Francisco, Itatiba, SP, Brasil, 2005.

[5] PARRAUD, R., BROCARD, E., LODI, Z., NAMORA, M., "Sistemas de isolamento para melhorar a qualidade do serviço em ambiente tropical”, In: Anais do XV SNPTEE - Seminário Nacional de Produção e Transmissão de Energia Elétrica, pp. 1-7 (GLT/12), Foz do Iguaçu, Outtubro 1999.

[6] DOYLE, P.J., Glass making today: an introduction to current practice in glass manufacture, Sheffield, British Glass Industry Research Association \& Portcullis Press, 1979. 
[7] BLANK, K., "Some practical aspects of thermally strengthened glass”, In: Strength of inorganic glass, New York, Plenum Press, Ed. C.R. Kurkjian, pp. 485-499, 1985.

[8] MCMASTER, R.A., SHETTERLY, D.M., BUENO, A.G., “Annealed and tempered glass”, In: Ceramic and glasses - Engineered materials handbook, v. 4, EUA, ASM International, pp. 453-459, 1991.

[9] BARTHOLOMEW, R.F., “Ion-exchange”, In: Ceramic and glasses - Engineered materials handbook, v. 4, ASM International, pp. 460-463, 1991.

[10] TANDON, R., GLASS, J.S., “Controlling the fragmentation behavior of stressed glasses”, In: Fracture Mechanics of Ceramics: active materials, nanoscale materials, composites, glass, and fundamentals, EUA, Plenum Press, Ed. K. White et al., pp. 77-92, 2005.

[11] ORGAZ, F., NAVARRO, J.M.F., "Prediction of results of strengthening glass by using the misfitting sphere theory”, In: Strength of inorganic glass, New York, Plenum Press, Ed. C. R. Kurkjian, pp. 513-523, 1985.

[12] NAVARRO, J.M.F., El vidrio: constitución, fabricación, propiedades, 2 ed., Madrid, Consejo Superior de Investigaciones Científicas, 1991.

[13] NORBERG, E.M., MOCHEL, L.E., GARFINKEL, M.H., OLCOTT, S.J., "Strengthening by ion exchange”, Journal of the American Ceramic Society, v. 47, n. 5, pp. 215-219, January 1964.

[14] SINTON, C.W., LACOURSE, W.C., O’CONNELL, M.J., "Variations in $\mathrm{K}^{+}-\mathrm{Na}^{+}$ion exchange depth in commercial and experimental float glass compositions”, Materials Research Bulletin, v. 34, n. 14/15, pp. 2351-2359, April 1999.

[15] KISTLER, S.S., "Stresses in glass produced by non uniform exchange of monovalent ions”, Journal of the American Ceramic Society, v. 45, n. 2, pp. 59-68, June 1962.

[16] VARNER, J.R., “The practical strength of glass”, In: Strength of Inorganic Glass, New York, Plenum Press, Ed. C.R. Kurkjian, pp. 389-406, 1985.

[17] SCHAEFFER, H.A., “Thermal and chemical strengthening of glass - review and outlook”, In: Strength of Inorganic Glass, New York, Plenum Press, Ed. C.R. Kurkjian, pp. 469-483, 1985.

[18] GREEN, D.J., TANDON, R., SGLAVO, V.M., “Crack arrest and multiple cracking in glass through the use of designed residual stress profiles”, Science, v. 283, pp. 1295-1297, March 1999.

[19] TANDON, R., GREEN, D.J., "Crack stability and T-curves due to macroscopic residual compressive stress profile”, Journal of the American Ceramic Society, v. 74, n. 8, pp. 1981-1986, 1991.

[20] SGLAVO, V.M., LARENTIS, L., GREEN, D.J., "Flaw-insensitive ion-exchanged glass: I, theoretical aspects”, Journal of the American Ceramic Society, v. 84, n. 8, pp. 1827-1831, June 2001.

[21] SGLAVO, V.M., GREEN, D.J., "Flaw-insensitive ion-exchanged glass: II, production and mechanical performance”, Journal of the American Ceramic Society, v. 84, n. 8, pp. 1832-1838, June 2001.

[22] ABRAMS, M.B., GREEN, D.J., GLASS, S.J., "Fracture behavior of engineered stress profile soda lime silicate glass”, Journal of Non-Crystalline Solids, v. 321, pp. 10-19, June 2003.

[23] ABRAMS, M.B., Crack propagation and fracture in engineering stress profile glass, Tese de D.Sc, Pensylvania State University, Pensylvania, EUA, 2004.

[24] SHEN, J., GREEN, D.J., "Variable-temperature ion-exchanged engineered stress profile (ESP) glasses”, Journal of the American Ceramic Society, v. 86, n. 11, pp. 1979-1981, December 2003.

[25] ANUSAVICE, K.J., SHEN, C., VERMOST, B., CHOW, B., "Strengthening of porcelain by ion exchange subsequent to thermal tempering”, Dental Materials, v. 8, n. 3, pp. 149-152, May 1992. 
[26] BIRTCH, E.M., SHELBY, J.E., "Effect of water in the melting atmosphere on the transformation temperature of commercial glasses”, In: Advances in fusion and processing of glass III, Ceramic Transactions, Westerville, The American Ceramic Society, Ed. J. R. Varner et al., v. 141, pp. 347362, 2004.

[27] SHELBY, J.E., MESKO, M.G., SHULMAN, H., EDSON, D.L., "Properties of soda-lime-silica glasses”, In: Advances in fusion and processing of glass III, Ceramic Transactions, Westerville, The American Ceramic Society, Ed. J. R. Varner et al., v. 141, pp. 371-378, 2004.

[28] ANÔNIMO (2004), NBR 5032: Isoladores para linhas aéreas com tensões acima de $1000 \mathrm{~V}$ Isoladores de porcelana ou vidro para sistemas de corrente alternada. Rio de Janeiro, ABNT Associação Brasileira de Normas Técnicas.

[29] ROSA, V., Efeito da troca iônica nos parâmetros de Weibull, de crescimento subcrítico de trincas e no comportamento de curva $R$ de uma porcelana odontológica, Dissertação de M.Sc., Universidade de São Paulo, São Paulo, SP, Brasil, 2007.

[30] HESSENKEMPER, H., "Mechanical strength increase during the forming process of glass”, In: Advances in fusion and processing of glass III, Ceramic Transactions, Westerville, The American Ceramic Society, Ed. J. R. Varner et al., v. 141, pp. 259-264, 2004.

[31] GUILLEMET, C., "Current challenges concerning the mechanical strength of glass products", In: Strength of inorganic glass, New York, Plenum Press, Ed. C.R. Kurkjian, pp. 407-418, 1985.

[32] KINGERY, W.D., BOWEN, H.K., UHLMANN, D.R., Introduction to ceramics, 2 ed., New York, John Willey \& Sons, 1976.

[33] HANNINK, R.H.J., KELLY, P.M., MUDDLE, B.C., “Transformation toughening in zirconia-containing ceramics”, Journal of the American Ceramic Society, v. 83, n. 3, pp. 461-487, March 2000.

[34] YOSHIMURA, H.N., MOLISANI, A.L., NARITA, N.E., GONÇALVES, M.P., CAMPOS, M.F. DE, "Zircônia parcialmente estabilizada de baixo custo produzida por meio de mistura de pós com aditivos do sistema MgO-Y ${ }_{2} \mathrm{O}_{3}-\mathrm{CaO}$ ”, Cerâmica, v. 53, n. 326, pp. 116-132, June 2007. 